\title{
A role for cyclooxygenase-1 in $\beta$-amyloid-induced neuroinflammation
}

\author{
Eduardo Candelario-Jalil
}

\author{
Department of Neurology, University of New Mexico, Health Sciences Center MSC10 5620, Albuquerque, \\ NM 87131-0001, USA
}

\begin{abstract}
Running title: COX-1 and neuroinflammation
Key words: $\beta$-amyloid, COX-1, microglia, neuroinflammation, Alzheimer's disease, oxidative stress, COX-2 Correspondence: Eduardo Candelario-Jalil, PhD, Department of Neurology, University of New Mexico, Health Sciences Center MSC10 5620, 915 Camino de Salud NE, Albuquerque, NM 87131-0001, USA

Received: 04/06/09; accepted: 04/13/09; published on line: 04/13/09

E-mail: ECandelario-Jalil@salud.unm.edu

Copyright: (C) Candelario-Jalil. This is an open-access article distributed under the terms of the Creative Commons Attribution License, which permits unrestricted use, distribution, and reproduction in any medium, provided the original author and source are credited
\end{abstract}

Alzheimer's disease (AD) is a chronic neurodegenerative disorder characterized by progressive cognitive decline and memory loss. Accumulation of $\beta$ amyloid $(\mathrm{A} \beta)$ and tau protein are believed to be important pathological features of AD [1]. Results from a large number of studies suggest that neuroinflammation is a key contributor to neuronal loss in AD. Anti-inflammatory drugs, in particular nonsteroidal anti-inflammatory drugs (NSAIDs), seem to be beneficial in terms of slowing the development of $\mathrm{AD}$, as shown by several epidemiological studies [2-4]. Inhibition of cyclooxygenase (COX) activity is the main mechanism of action of NSAIDs. Two COX isoforms, COX-1 and COX-2, have been identified. Clinical studies evaluating the effects of NSAIDs or COX-2 selective inhibitors on AD have failed to show therapeutic efficacy. Some authors have suggested that the main reason for this is that COX-1 and COX-2 are involved in AD neuropathology in a preclinical stage of the disease. This explains the positive reports of the epidemiological studies and the negative findings in clinical trials with COX inhibitors [5, 6]. Long-term use of NSAIDs might reduce the risk of $\mathrm{AD}$, if the treatment starts before the onset of $\mathrm{AD}$ dementia [7].

There is considerable debate on the relative contribution of each $\mathrm{COX}$ isoform to $\mathrm{AD}$ pathology. In $\mathrm{AD}$ brains, neuronal COX-2 levels have been found to be either elevated in early stages [8-10] or decreased in end-stage [11]. It is interesting to note that an upregulation in early $\mathrm{AD}$ and reduction of $\mathrm{COX}-2$ in advanced $\mathrm{AD}$ correlates very nicely with the levels of prostaglandin $\mathrm{E}_{2}\left(\mathrm{PGE}_{2}\right)$ in the CSF, which are increased in subjects with mild memory impairment (probable AD diagnosis) and decreased with increasing severity of AD dementia $[12,13]$. COX-2 is expressed in neurons, but not in astrocytes or microglia in AD brains [5]. Transgenic mice in which human COX-2 is overexpressed constitutively in neurons develop age-dependent cognitive deficits that are associated with a parallel agedependent increase in neuronal apoptosis and astrocytic activation [14]. Overexpression of COX-2 in APPswePS1dE9 mice leads to age-dependent cognitive deficits in females but not male mice, without significantly affecting $A \beta$ accumulation. The cognitive deficits in female COX-2/APPswe-PS1dE9 mice are reversed with administration of the COX-2 selective inhibitor celecoxib [15]. This suggests a sex-dimorphic involvement of $\mathrm{COX}-2$ in $\mathrm{AD}$ neuropathology. Selective inhibition of COX-2, but not COX-1, prevented the suppression of hippocampal long-term potentiation (LTP) induced by $A \beta_{1-42}$. The NSAIDs, ibuprofen and naproxen, and a selective COX-2 inhibitor restored memory function in Tg2576 mice 
overexpressing APP [16]. Interestingly, COX-1expressing microglia surrounds amyloid plaques [17]. There is no evidence that COX-1 expression in microglia is changed in $\mathrm{AD}$ brain [5]. However, accumulation of COX-1-expressing microglia in AD could result in local increase in prostaglandin synthesis and oxidative stress.

In a very recent article by Choi and Bosetti, published in the February issue of Aging, they report for the first time the effect of COX-1 gene deletion on the neurotoxicity associated with $A \beta$ [18]. These data provide strong experimental evidence linking COX-1 activity to neuronal loss following intracerebroventricular administration of $A \beta$. Authors found a dramatic inflammatory response within the CA1 and CA3 areas of the hippocampus in 3-month-old wildtype mice seven days after $A \beta_{1-42}$ peptide injection. This neuroinflammatory response was characterized by the presence of Iba-1-positive activated microglia, increased GFAP-immunoreactive astrocytes, and elevated oxidative stress markers. Interestingly, COX-1 deficient mice displayed a significant reduction in the number of activated microglia in the CA3 region of the hippocampus as well as in the number of GFAPpositive reactive astrocytes, indicating that $A \beta_{1-42}$ injection induced less severe glial activation in COX-1 knockout animals compared to wild-type control mice. In addition, COX-1 deficiency was associated with decreased oxidative damage, suggesting that enhanced COX-1 activity is a significant source of oxidative stress in $A \beta$-mediated neurotoxicity. Levels of $\mathrm{PGE}_{2}$, $\mathrm{PGF}_{2 \alpha}$ and thromboxane $\mathrm{B}_{2}\left(\mathrm{TXB}_{2}\right)$ were significantly reduced in COX-1 null mice compared with wild-type controls. More importantly, COX-1 deletion resulted in reduced neuronal damage following $A \beta_{1-42}$ administration, as shown by a reduced number of FluoroJade B (FJB)-positive cells in the hippocampus.

The classical view that COX-2 is more important than COX-1 in neuroinflammatory processes should be revisited. The data of Choi and Bosetti [18], together with findings from other studies [19-21] indicate that COX-1 is actively involved in brain injury induced by pro-inflammatory stimuli including $A \beta$, lipopolysaccharide (LPS) and TNF- $\alpha$. In some models of neuroinflammation, COX-2 deletion or pharmacological inhibition with selective agents exacerbate rather than reduce inflammation-related brain damage [22]. COX-1 is prominently expressed by microglia $[8,17]$. Due to the key role of microglia in neuroinflammation, it has been suggested that selective inhibition of COX-1, rather than COX-2, will be more effective in treating neuroinflammation and neurodegeneration [23].
Reduction in cognitive decline in $\mathrm{AD}$ patients was observed in a 6-month, double-blinded, placebocontrolled study with indomethacin, a non-selective, but a potent COX-1 inhibitor [24]. No beneficial effects were observed with the COX-2 selective inhibitors celecoxib and rofecoxib [25-29]. Based on these previous studies and their own data [18], Choi and Bosetti propose the intriguing hypothesis that the potential protective effects of NSAIDs in AD may be related to COX-1, but not COX-2 inhibition. In support of this notion, a previous study showed that neurons treated with COX-1 selective inhibitors are resistant to $\mathrm{A} \beta_{1-42}$ [30]. Moreover, COX-1 inhibition produced a profound inhibition of either LPS- or arachidonic acidinduced $\mathrm{PGE}_{2}$ synthesis in human microglia [31]. However, with the exception of one small pilot study [24], no therapeutic efficacy in AD clinical trials have been found with NSAIDs, including nonselective inhibitors such as naproxen and diclofenac, which inhibit both COX-1 and COX-2 [5, 26].

A major limitation of chronic COX-1 inhibitor treatment of $\mathrm{AD}$ patients is the gastrointestinal toxicity, due to the suppression of COX-1-mediated production of protective prostaglandins. In the pilot clinical study showing beneficial effects of indomethacin in $\mathrm{AD}$ patients, the dropout rate in the indomethacin group was approximately $40 \%$, mostly due to drug-related gastrointestinal adverse events [24]. There is obviously a risk attached to taking any drug. However, clinical demonstration of a positive benefit/risk ratio of NSAIDs in $\mathrm{AD}$ patients is missing. It has been questioned whether anti-inflammatory interventions are really a viable or even preventive option for $\mathrm{AD}$ [6].

It is still debatable whether targeting neuroinflammatory events in $\mathrm{AD}$, primarily microglial activation, is a promising therapeutic option. In AD, microglia accumulate in senile plaques and may have a dual role, either digesting or contributing to the formation of $A \beta$ plaques [1]. The idea of removal of senile plaque constituents by microglia was first proposed by Timmer in 1925, who suggested that these cells were mobilized to phagocytose toxic products and formed the core of senile plaques [32]. Clusters of microglial cells with rounded and phagocytic phenotypes are found in fibrillar $\mathrm{A} \beta$ deposits in the neocortex of $\mathrm{AD}$ brain [33]. In an elegant study published in Neuron, Simard and colleagues showed that it is the bone marrow-derived microglia, and not their counterparts resident in the brain, that have the ability to promote the clearance and phagocytosis of $A \beta$ [34]. On the other hand, the production of inflammatory mediators by microglia might contribute to the formation of $\mathrm{A} \beta$ plaques [35]. Therefore, the specific role of these cells in the 
evolution of the senile plaques in $\mathrm{AD}$ is still under debate.

Early accumulation of microglial cells in AD delays disease progression by facilitating clearance of $A \beta$ before formation of senile plaques. However, persistent $\mathrm{A} \beta$ accumulation despite increasing microglial numbers indicate that the capacity of microglia to phagocytose $\mathrm{A} \beta$ may be impaired with age. A recent study indicates that the progression of $A \beta$ plaque formation is associated with an aging-dependent dysfunction of microglia in the PS1-APP transgenic mice, an AD mouse model [36]. The number of senile-like plaques and microglia associated with these plaques are increased as the mice age. Microglia from old PS1-APP mice, but not from younger mice, have a decrease capacity to clear $A \beta$. This may be related to the increased production of proinflammatory mediators and to a downregulation of genes involved in $A \beta$ removal [36]. These results illustrate the dichotomous role of microglia in AD pathology.

Data from the report by Choi and Bosetti [18] are exciting and have potential clinical implications. This study will fuel future experimentation to elucidate the specific role of each COX isoform in neuroinflammation and neurodegenerative processes. It remains to be determined how COX-1 inhibition modifies the early beneficial function of activated microglia in $\mathrm{A} \beta$ clearance and whether COX-1 inhibition is protective against neuronal loss in other models of AD such as the PS1-APP transgenic mice. Is COX-1 inhibition also protective in older animals and females? Future research will definitely provide answers to these questions. Elucidating the role of neuroinflammatory events in AD may provide opportunities toward the development of new therapeutic strategies to tackle neurodegeneration associated with $\mathrm{AD}$ and possibly other neurodegenerative disorders.

\section{CONFLICT OF INTERESTS STATEMENT}

The author of this manuscript has no conflict of interests to declare.

\section{REFERENCES}

1. Boche $D$, Nicoll JA. The role of the immune system in clearance of Abeta from the brain. Brain Pathol. 2008; 18:267-278.

2. McGeer PL, Schulzer M, McGeer EG. Arthritis and antiinflammatory agents as possible protective factors for Alzheimer's disease: a review of 17 epidemiologic studies. Neurology. 1996; 47:425-432.

3. in $t^{\prime}$ Veld BA, Ruitenberg A, Hofman A, Launer $L$, van Duijn $\mathrm{CM}$, Stijnen $\mathrm{T}$, Breteler $\mathrm{MM}$, Stricker $\mathrm{BH}$. Nonsteroidal antiinflammatory drugs and the risk of Alzheimer's disease. $\mathrm{N}$ Engl J Med. 2001; 345:1515-1521.

4. McGeer PL, McGeer EG. NSAIDs and Alzheimer disease: epidemiological, animal model and clinical studies. Neurobiol Aging. 2007; 28:639-647.

5. Hoozemans JJ, Rozemuller JM, van Haastert ES, Veerhuis $R$, Eikelenboom P. Cyclooxygenase-1 and -2 in the different stages of Alzheimer's disease pathology. Curr Pharm Des. 2008; 14:1419-1427.

6. Hoozemans JJ, O'Banion MK. The role of COX-1 and COX-2 in Alzheimer's disease pathology and the therapeutic potentials of non-steroidal anti-inflammatory drugs. Curr Drug Targets CNS Neurol Disord. 2005; 4:307-315.

7. Zandi PP, Anthony JC, Hayden KM, Mehta K, Mayer L, Breitner JC. Reduced incidence of AD with NSAID but not $\mathrm{H} 2$ receptor antagonists: the Cache County Study. Neurology. 2002; 59:880886.

8. Hoozemans JJ, Rozemuller AJ, Janssen I, De Groot CJ, Veerhuis $R$, Eikelenboom P. Cyclooxygenase expression in microglia and neurons in Alzheimer's disease and control brain. Acta Neuropathol. 2001; 101:2-8.

9. Pasinetti GM, Aisen PS. Cyclooxygenase-2 expression is increased in frontal cortex of Alzheimer's disease brain. Neuroscience. 1998; 87:319-324.

10. Fujimi K, Noda K, Sasaki K, Wakisaka Y, Tanizaki Y, lida M, Kiyohara $Y$, Kanba S, Iwaki T. Altered expression of COX-2 in subdivisions of the hippocampus during aging and in Alzheimer's disease: the Hisayama Study. Dement Geriatr Cogn Disord. 2007; 23:423-431.

11. Yermakova AV, O'Banion MK. Downregulation of neuronal cyclooxygenase-2 expression in end stage Alzheimer's disease. Neurobiol Aging. 2001; 22:823-836.

12. Combrinck $M$, Williams J, De Berardinis MA, Warden $D$, Puopolo M, Smith AD, Minghetti L. Levels of CSF prostaglandin E2, cognitive decline, and survival in Alzheimer's disease. J Neurol Neurosurg Psychiatry. 2006; 77:85-88.

13. Montine TJ, Sidell KR, Crews BC, Markesbery WR, Marnett LJ, Roberts LJ, 2nd, Morrow JD. Elevated CSF prostaglandin E2 levels in patients with probable AD. Neurology. 1999; 53:1495-1498.

14. Andreasson KI, Savonenko A, Vidensky S, Goellner JJ, Zhang Y, Shaffer A, Kaufmann WE, Worley PF, Isakson P, Markowska AL. Age-dependent cognitive deficits and neuronal apoptosis in cyclooxygenase-2 transgenic mice. J Neurosci. 2001; 21:81988209.

15. Melnikova $T$, Savonenko A, Wang $Q$, Liang $X$, Hand T, Wu L, Kaufmann WE, Vehmas A, Andreasson KI. Cycloxygenase-2 activity promotes cognitive deficits but not increased amyloid burden in a model of Alzheimer's disease in a sex-dimorphic pattern. Neuroscience. 2006; 141:1149-1162.

16. Kotilinek LA, Westerman MA, Wang Q, Panizzon K, Lim GP, Simonyi A, Lesne S, Falinska A, Younkin LH, Younkin SG, Rowan M, Cleary J, Wallis RA, Sun GY, Cole G, Frautschy S, Anwyl R, Ashe $\mathrm{KH}$. Cyclooxygenase-2 inhibition improves amyloid-betamediated suppression of memory and synaptic plasticity. Brain. 2008; 131:651-664.

17. Yermakova AV, Rollins J, Callahan LM, Rogers J, O'Banion MK. Cyclooxygenase-1 in human Alzheimer and control brain: quantitative analysis of expression by microglia and CA3 hippocampal neurons. J Neuropathol Exp Neurol. 1999; 58:11351146. 
18. Choi SH, Bosetti F. Cyclooxygenase-1 null mice show reduced neuroinflammation in response to b-amyloid. Aging. 2009; 1:234-244.

19. Choi SH, Langenbach $R$, Bosetti $F$. Genetic deletion or pharmacological inhibition of cyclooxygenase-1 attenuate lipopolysaccharide-induced inflammatory response and brain injury. FASEB J. 2008; 22:1491-1501.

20. Candelario-Jalil E, de Oliveira AC, Graf $S$, Bhatia HS, Hull M, Munoz E, Fiebich BL. Resveratrol potently reduces prostaglandin E2 production and free radical formation in lipopolysaccharideactivated primary rat microglia. J Neuroinflammation 2007; 4:25. 21. Candelario-Jalil E, Taheri S, Yang Y, Sood R, Grossetete $M$, Estrada EY, Fiebich BL, Rosenberg GA. Cyclooxygenase inhibition limits blood-brain barrier disruption following intracerebral injection of tumor necrosis factor-alpha in the rat. J Pharmacol Exp Ther. 2007; 323:488-498.

22. Aid S, Langenbach R, Bosetti F. Neuroinflammatory response to lipopolysaccharide is exacerbated in mice genetically deficient in cyclooxygenase-2. J Neuroinflammation. 2008; 5:17.

23. Choi SH, Aid S, Bosetti F. The distinct roles of cyclooxygenase-1 and -2 in neuroinflammation: implications for translational research. Trends Pharmacol Sci. 2009; 30:174-181.

24. Rogers J, Kirby LC, Hempelman SR, Berry DL, McGeer PL, Kaszniak AW, Zalinski J, Cofield M, Mansukhani L, Willson P, et al. Clinical trial of indomethacin in Alzheimer's disease. Neurology. 1993; 43:1609-1611.

25. Aisen PS, Thal LJ, Ferris SH, Assaid C, Nessly ML, Giuliani MJ, Lines CR, Norman BA, Potter WZ. Rofecoxib in patients with mild cognitive impairment: further analyses of data from a randomized, double-blind, trial. Curr Alzheimer Res. 2008; 5:7382.

26. Aisen PS, Schafer KA, Grundman M, Pfeiffer E, Sano M, Davis $\mathrm{KL}$, Farlow MR, Jin S, Thomas RG, Thal L. Effects of rofecoxib or naproxen vs placebo on Alzheimer disease progression: a randomized controlled trial. JAMA. 2003; 289:2819-2826.

27. Reines SA, Block GA, Morris JC, Liu G, Nessly ML, Lines CR, Norman BA, Baranak CC. Rofecoxib: no effect on Alzheimer's disease in a 1-year, randomized, blinded, controlled study. Neurology. 2004; 62:66-71.

28. Thal $L$, Ferris $S H$, Kirby $L$, Block GA, Lines CR, Yuen E, Assaid C, Nessly ML, Norman BA, Baranak CC, Reines SA. A randomized, double-blind, study of rofecoxib in patients with mild cognitive impairment. Neuropsychopharmacology. 2005; 30:1204-1215.

29. Soininen H, West C, Robbins J, Niculescu L. Long-term efficacy and safety of celecoxib in Alzheimer's disease. Dement Geriatr Cogn Disord. 2007; 23:8-21.

30. Bate C, Veerhuis R, Eikelenboom P, Williams A. Neurones treated with cyclo-oxygenase-1 inhibitors are resistant to amyloid-beta1-42. Neuroreport. 2003; 14:2099-2103.

31. Hoozemans JJ, Veerhuis R, Janssen I, van Elk EJ, Rozemuller AJ, Eikelenboom P. The role of cyclo-oxygenase 1 and 2 activity in prostaglandin $E(2)$ secretion by cultured human adult microglia: implications for Alzheimer's disease. Brain Res. 2002; 951:218-226.

32. Timmer AP. Der Anteil der Mikroglia un Makroglia am Aufbau der senilen Plaques. Z Neurol. 1925; 98:43-58.

33. Akiyama H, Barger S, Barnum S, Bradt B, Bauer J, Cole GM, Cooper NR, Eikelenboom P, Emmerling M, Fiebich BL, Finch CE, Frautschy S, Griffin WS, Hampel H, Hull M, Landreth G, Lue L, Mrak R, Mackenzie IR, McGeer PL, O'Banion MK, Pachter J,
Pasinetti G, Plata-Salaman C, Rogers J, Rydel R, Shen Y, Streit W, Strohmeyer R, Tooyoma I, Van Muiswinkel FL, Veerhuis R, Walker D, Webster S, Wegrzyniak B, Wenk G, Wyss-Coray T. Inflammation and Alzheimer's disease. Neurobiol Aging. 2000; 21:383-421.

34. Simard AR, Soulet D, Gowing G, Julien JP, Rivest S. Bone marrow-derived microglia play a critical role in restricting senile plaque formation in Alzheimer's disease. Neuron. 2006; 49:489502.

35. Eikelenboom $P$, Veerhuis $R$, Scheper W, Rozemuller AJ, van Gool WA, Hoozemans JJ. The significance of neuroinflammation in understanding Alzheimer's disease. J Neural Transm. 2006; 113:1685-1695.

36. Hickman SE, Allison EK, El Khoury J. Microglial dysfunction and defective beta-amyloid clearance pathways in aging Alzheimer's disease mice. J Neurosci. 2008; 28:8354-8360. 